\title{
Key Technologies of Finite Element Modeling of Machine Tools Based on ANSYS Platform
}

\author{
Haitao Liu ${ }^{1, a}$, Wenming Wei ${ }^{2}$ \\ ${ }^{1}$ School of Mechatronic Engineering, Xi'an Technological University, China \\ ${ }^{2}$ State Key Laboratory for Manufacturing Systems Engineering, Xi' an Jiaotong University, China
}

\begin{abstract}
In order to establish the joint interface elements more quickly, and to analyze the dynamic characteristics of machine tools under different states (such as headstock at different position), the CAD model of machine tool must be divided effectively, so that the hexahedron elements with specified size can be generated in the area of the joint interfaces, so that the nodes on the joint surfaces can be coincident. Using APDL technology, the linear spring-damped elements are quickly established on the fixed joint (bolt joint interface between the bed and base) and the moving joint (guideway-slider, screw-nut). The experimental and simulation results show that the method is effective.It has considerable accuracy, and can greatly speed up the machine tool modeling, especially the processing speed of the joint interfaces.
\end{abstract}

\section{Introduction}

The finite element model is the basic of analyzing the static and dynamic characteristics of machine tool ${ }^{[1-2]}$, which is established by CAD model. It is very important to divide the CAD model and deal with the joint surface reasonably. The method of connecting the corresponding nodes on the two parts to establish the spring-damped elements is used to approximate the interface model ${ }^{[3-4]}$.

Because the topological structure of machine tool parts is complex, it is difficult to mesh all of them into hexahedron elements. The manual connection of two nodes to establish spring-damped elements is too complicated to be feasible between two parts meshed into tetrahedron elements. Therefore, the CAD model of the machine tool must be divided into two parts: the joint interface part and the non-joint interface part, which the former is meshed into hexahedron elements and the latter tetrahedron elements. Based on this, the method of quickly establishing the spring-damped elements is feasible. The vertical machine tool in Figure 1 is taken as an example to illustrate this method.

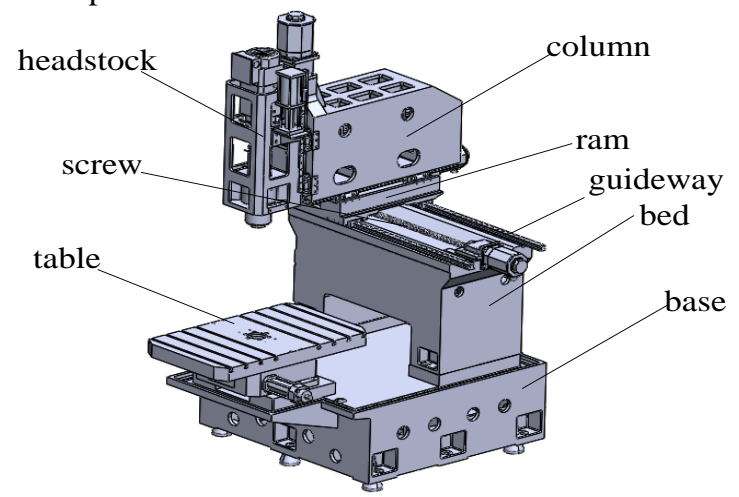

Figure 1. The CAD model of vertical machine tool

\section{Finite Element Model}

\subsection{Division of fixed joint interfaces}

The bolted connection between the base and the bed in Figure1, is a typical fixed joint interface. The two parts near the interface are divided according to the topological relation needed to divide the hexahedron mesh, which is shown in Figure 2. Before meshing, the components belonging to the same part need to be glued together, and then the components belonging to the joint interface are meshed into hexahedron elements, and the components that not belonging to the joint interface are meshed into tetrahedrons, as shown in Figure 3.

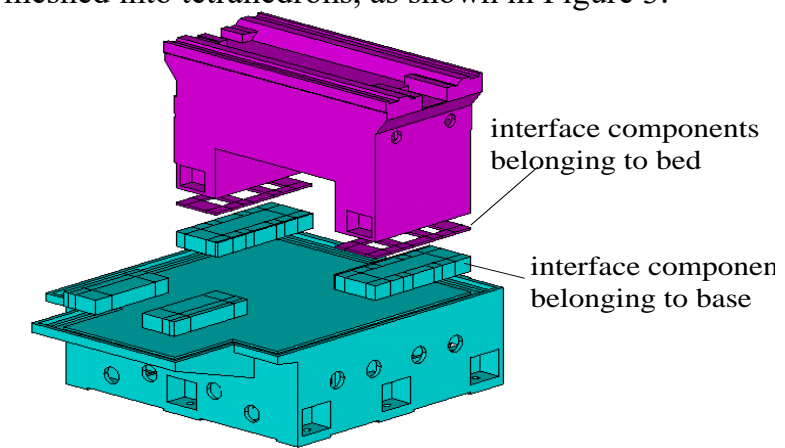

Figure 2. Topological division of bed and base

\footnotetext{
* Corresponding author: 429059044@qq.com
} 


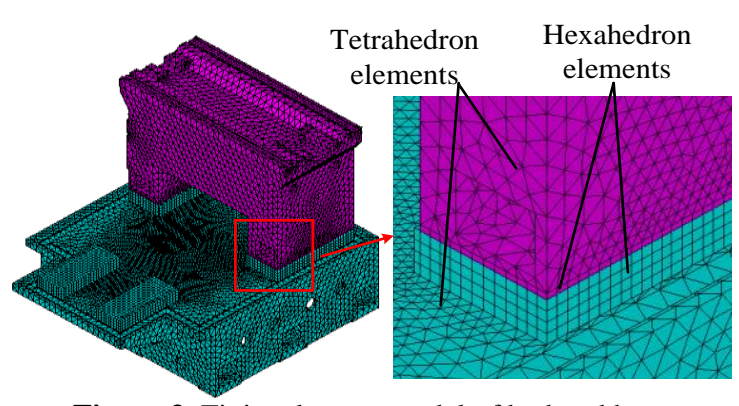

Figure 3. Finite element model of bed and base

\subsection{Placement of Spring elements for fixed joint interfaces}

First of all, the overall stiffness $K$ of the joint surface should be calculated or tested by experiment ${ }^{[4-5]}$. The stiffness is related to the preload $f$ of bolts and the gravity load of the parts. The mesh in Figure 3 makes the corresponding nodes of the two parts on the joint interface coincide with each other, so that the APDL commands are used in batch mode to quickly establish the joint interface elements.

Assuming that the stiffness of each element is the same, the stiffness of each spring-damped element are $: k$ $=K / n$, which $n$ is the number of nodes on the joint interface, as shown in Figure 4.

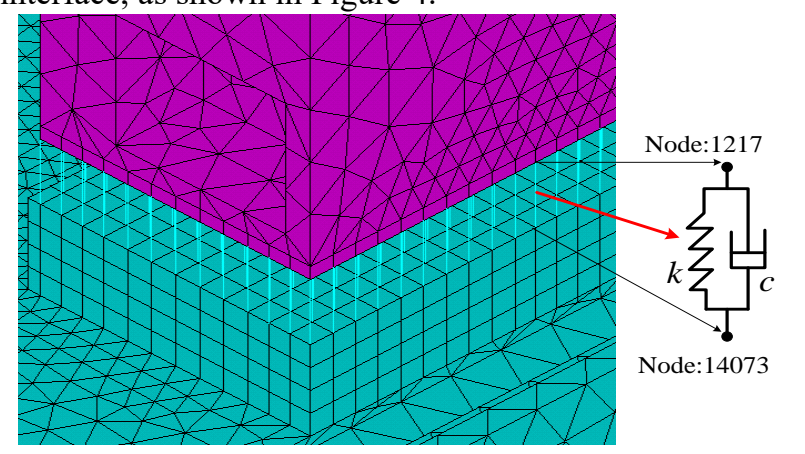

Figure 4. Spring-damped elements between bed and base (Nodes 1217 and Node14073 have the same spatial coordinates, $n=888$ )

The APDL commands for batching creation of the joint interface spring-damped elements are as follows:

! define element type and real constants

$\mathrm{Kx}$ bc $=5 \mathrm{e} 07$

$\mathrm{Ky \_ bc}=7.5 \mathrm{e} 07$

$\mathrm{Kz}$ bc $=5 \mathrm{e} 07$

$\mathrm{R}, 2, \mathrm{Kx}$ bc, ,,.,

RMORE, - Kx_bc, , , , , ,

RMORE,Ky $\mathrm{bc},,,,,$, ,

RMORE,-Ky_bc, , , , ,Kz_bc,

RMORE, , , , , ,-Kz_bc,

ET,2, MATRIX27, , ,4

Real,2

! The joint interface consists of 18 areas

*DIM,Arealist,array, 18

! 506 is the area number

Arealist $(1)=506$ Arealist $(2)=599$

Arealist $(17)=595$

Arealist $(18)=503$

${ }^{*} \mathrm{DO}, \mathrm{j}, 1,18,1$

ASEL,S,,,Arealist(j)

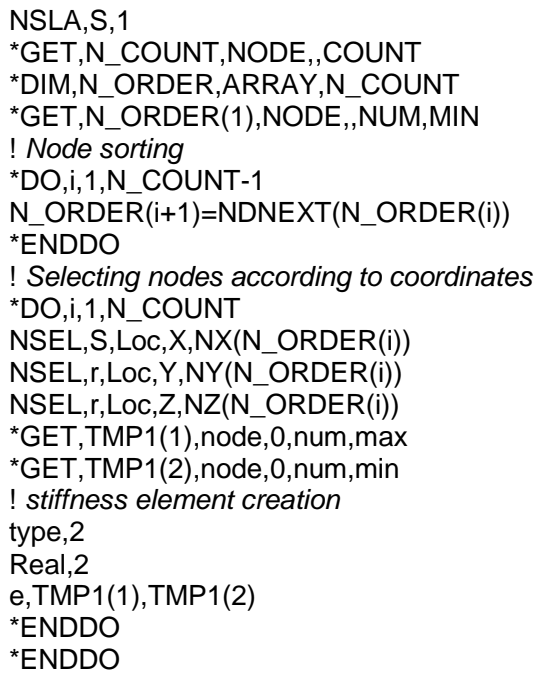

\subsection{Division of moving joint interfaces}

Figure 5 is the $x$-direction rolling guideway with a contact angle of 45 degrees, which is a typical moving joint interface. In finite element modeling, the steel ball is usually simplified as a spring element, so based on the simplification of the shape of the guideway and slider, it must ensure that the nodes belonging to the guideway and slider respectively coincide in order to facilitate the batch mode application of the spring element establishment by the subsequent APDL commands.
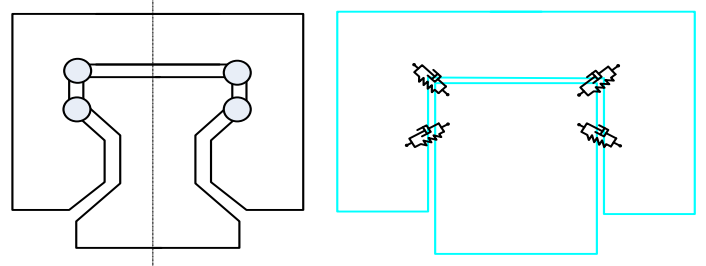

Figure 5. $x$-direction guideway-slider and its simplified model

The static and dynamic behaviors of the whole machine tool change when the column moves to different positions along the $x$-axis. In order not to build the model repeatedly for the subsequent calculations, it is also necessary to divide the guideway into several parts with a certain length, as well as some slight adjustments of the length of slider. Finally, the model should be divided according to the hexahedron meshing requirement. As shown in Figure 6, the basic element length of line is set to $25 \mathrm{~mm}$, since all entities in the model are integer times the length of 25 along the $x$ direction. Therefore, the guideway-slider can be divided into hexahedron solid elements with $25 \mathrm{~mm}$ length along $x$-direction, as shown in Figure 7. 

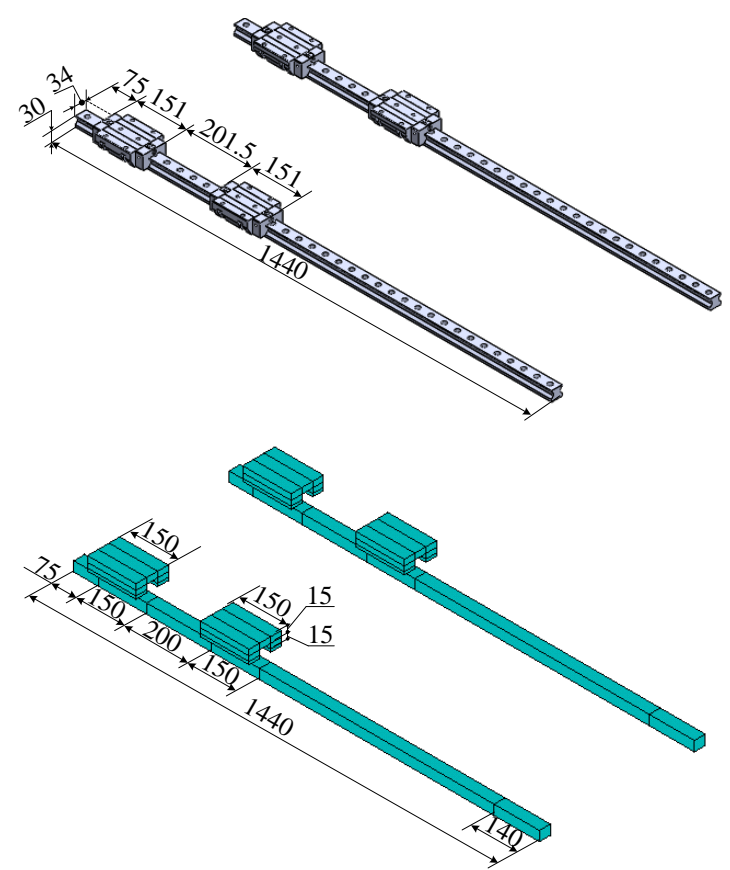

Figure 6. Topological division of guideway-slider

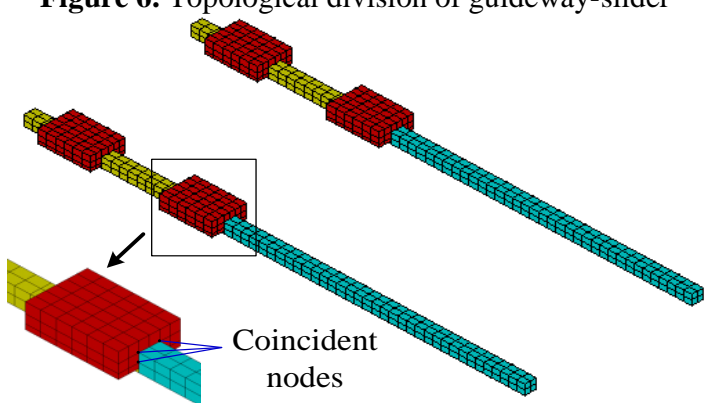

Figure 7. Finite element model of guideway-slider

\subsection{Placement of Spring elements for moving joint interfaces}

Similar to the fixed joint interface, it is also necessary to calculate or test the total stiffness of the joint interface $K$, which is related to the preload of the guideway and the gravity of the parts. In Figure 7 above, the division and meshing make the corresponding nodes on the four lines of guideway and slider coincide with each other.

Assuming that each element has the same stiffness, Therefore, the stiffness of each spring-element is: $k_{n}$ $=K / n, n=7$, and similar APDL commands can be used to apply the spring element in batch mode to the corresponding nodes.

\subsection{Finite elements mode of Screw-nut-bearing- motor system}

The finite element model of the whole machine should also include screw-nut-bearing joint interfaces, the method of division and placement of spring elements is the same as discussed above. In addition, the servo motor can be simplified as a lumped mass element, as shown in Figure 8.

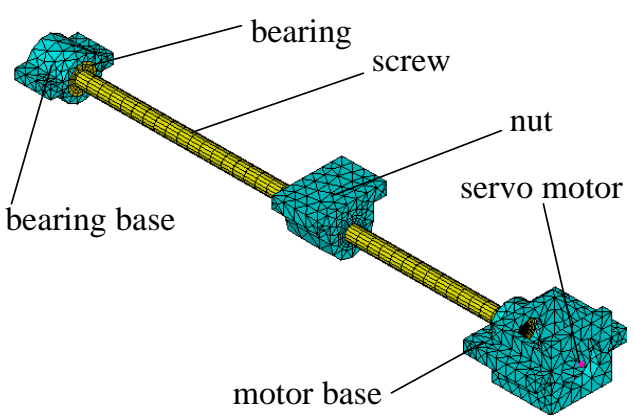

Figure 8. Finite elements model of screw-nut-bearing-motor system

\subsection{Finite elements mode of the whole machine tool system}

The finite element model of the whole machine system is shown in Figure 9, with a total of 161419 elements, including 4528 hexahedron elements, 155089 tetrahedron elements, 1798 spring elements and 4 mass elements.

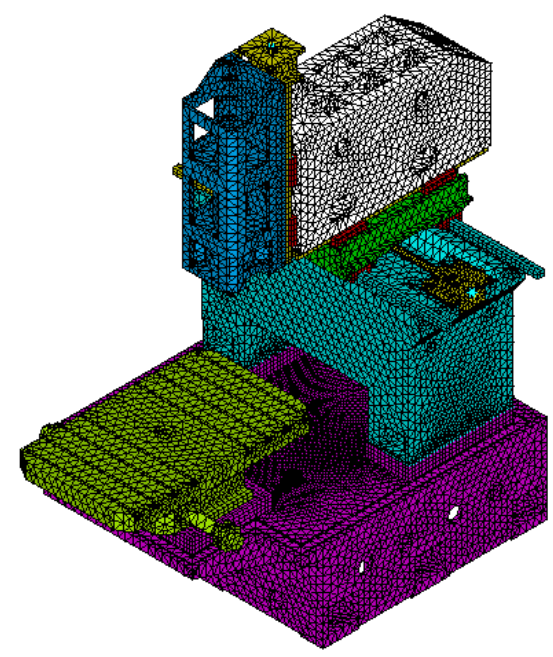

Figure 9. Finite element model of the whole machine system

\section{Comparison between simulation and experiment}

The dynamic characteristics of the whole machine are simulated and analyzed by using the finite element model set up above. In order to verify the accuracy of the model, the modal test of the machine tool is carried out by hammering method, as shown in Figure 10, and the first-five natural frequencies of the machine tool are obtained.

In Table 1, the first-five natural frequencies obtained by finite element simulation of the machine tool are compared with the experimental results, in which the first-two modes are the rigid body modes of the whole machine caused by the foot-screws, and have little effect on the machine tool. Table 2 shows the comparison of the third, fourth and fifth modes of the simulation and the experiment. 

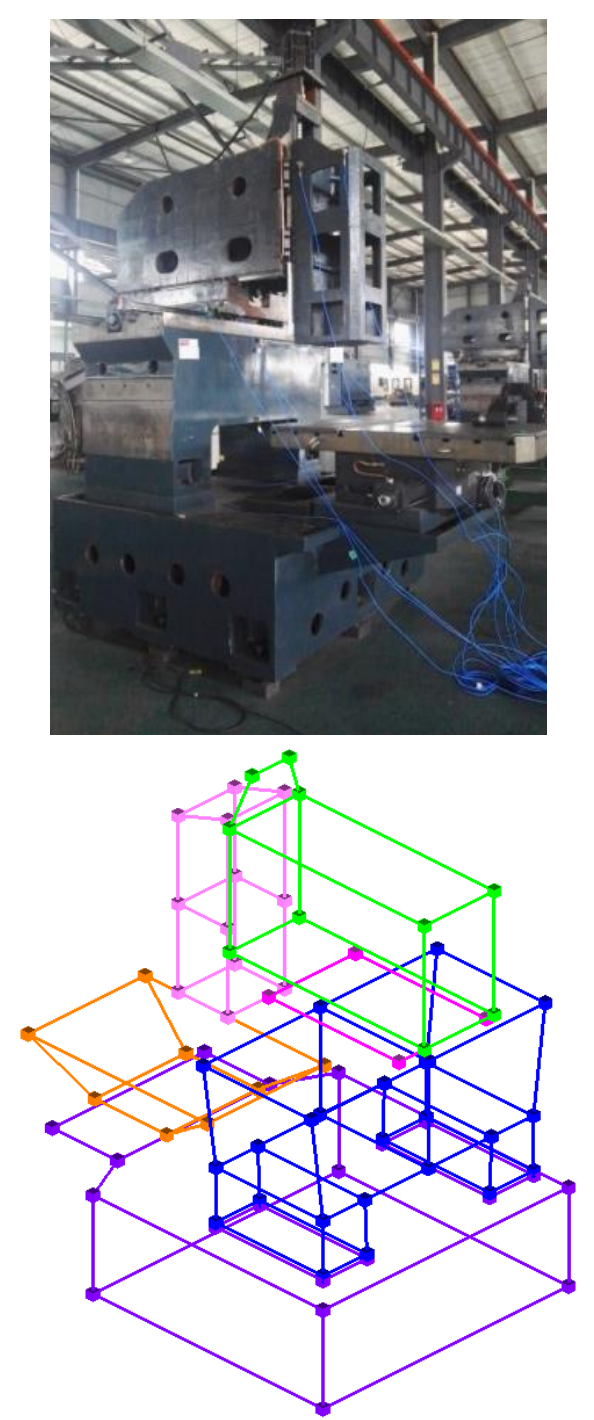

Figure 10. Modal test and testing point layout of the machine tool (totally 78 points)

Table 1. The first-five natural frequencies of the whole machine

\begin{tabular}{|c|c|c|c|c|c|c|}
\hline Mode & 1 & 2 & 3 & 4 & & 5 \\
\hline $\begin{array}{c}\text { Experimen } \\
\mathrm{t}(\mathrm{Hz})\end{array}$ & 22.6 & 47.1 & $\begin{array}{c}54 . \\
2\end{array}$ & 63.8 & $/$ & $\begin{array}{c}96 . \\
9\end{array}$ \\
\hline $\begin{array}{c}\text { Simulation } \\
(\mathrm{Hz})\end{array}$ & $/$ & $/$ & $\begin{array}{c}49 . \\
5\end{array}$ & 60.4 & $\begin{array}{c}79 . \\
9\end{array}$ & $\begin{array}{c}99 . \\
9\end{array}$ \\
\hline $\begin{array}{c}\text { Error } \\
(\%)\end{array}$ & $/$ & $/$ & 8.7 & 5.3 & $/$ & 3.1 \\
\hline
\end{tabular}

Table 2. The third, fourth and fifth modes of the whole machine

\begin{tabular}{|c|c|c|}
\hline $\begin{array}{c}\text { Mo } \\
\text { de }\end{array}$ & Experimental & Simulation \\
\hline
\end{tabular}

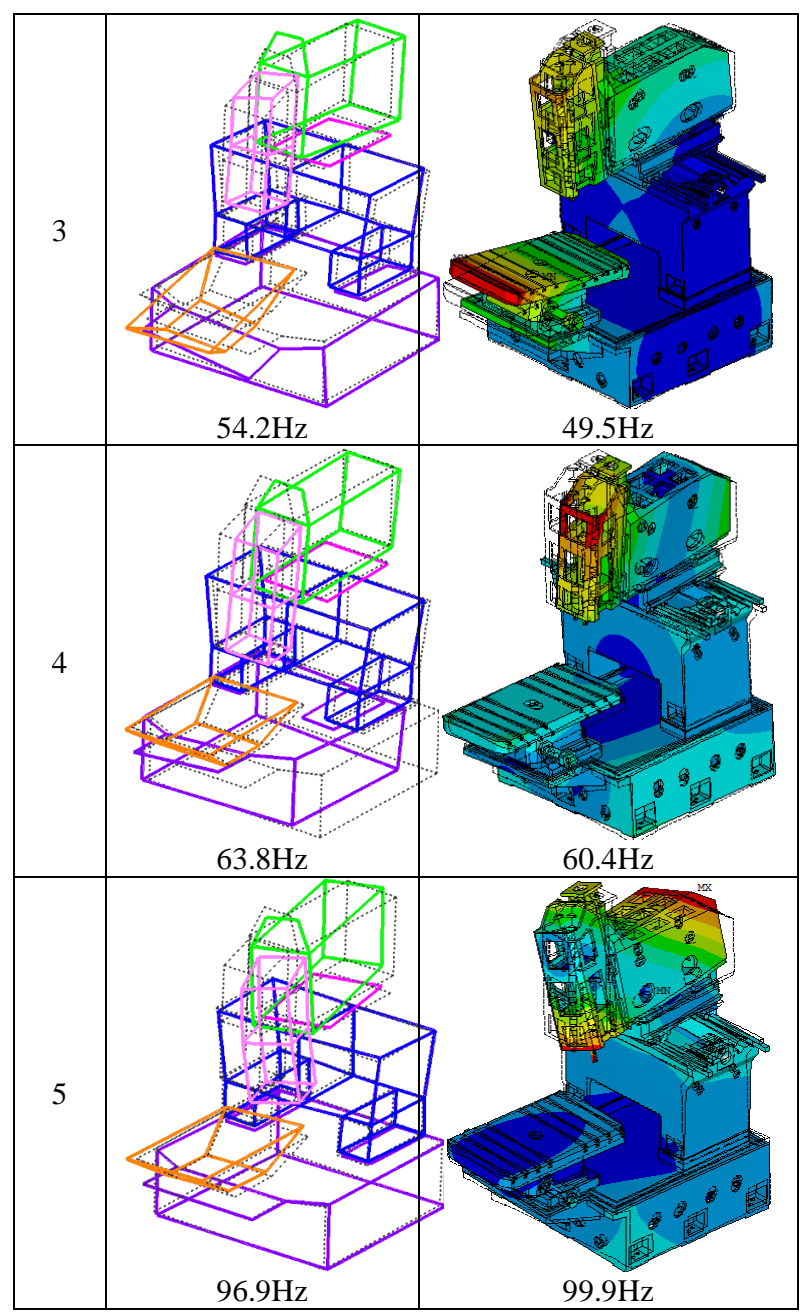

It can be seen from tables 1 and 12 that the error between simulation and experiment is less than $10 \%$ and the mode of vibration is the same. Therefore, the model of machine tool has high accuracy.

\section{Conclusions}

In this paper, a CAD model of vertical machine tool is divided to generate hexahedron in the area of the joint interfaces, which can make the nodes on the joint surfaces be coincident. Using APDL commands, the spring-damped elements are quickly established on the fixed joint and the moving joint. The experimental and simulation results show that the method is effective and time-saving, especially for the processing of the joint interfaces.

\section{References}

1. S.P. Li, J.P. Xu, X. Zhu, Z.S. Yin, S.W. Yuan. J. MACH. DESI, 34,1(2017).

2. X.H. Wu, Y.F. Ma, J.R. Zhang, J. VIB. SHOCK, 10(2009)

3. J.W. Fang, H.L. Wang, L.Q. Zhang, SH. Yuan, S. Ji, MANU. AUTO., 38, 2(2016).

4. H.L. Zhao, Q.X. Ding, M. Zeng, X.J. Liu. CHIN. J. MECH. ENG, 44,12(2008) 
5. Q. Miao , D.F. Hu. MACH. DESI.\&MANU, 9(2014) 